\title{
Bone Lesion
}

National Cancer Institute

\section{Source}

National Cancer Institute. Bone Lesion. NCI Thesaurus. Code C43260.

A localized pathological or traumatic structural change, damage, deformity, or discontinuity of bone. 